\title{
ARTICLE
}

\section{Raman studies of advanced gas-cooled reactor simulated spent nuclear fuels}

\author{
Richard J. Wilbraham ${ }^{\mathrm{a}}$, Nadya Rauff-Nisthar ${ }^{\mathrm{a}}$, Colin Boxall ${ }^{\mathrm{a}}$, Elizabeth A. Howett ${ }^{\mathrm{a}}$, David I. Hambley ${ }^{\mathrm{b}}$, Zoltan Hiezl $^{\mathrm{c}}$, \\ William E. Lee ${ }^{\mathrm{c}}$ and Cristiano Padovani ${ }^{\mathrm{d}}$

\begin{abstract}
${ }^{a}$ Engineering Department, Lancaster University, Lancaster, LA1 4YW, UK; ${ }^{b}$ Spent Fuel Management and Disposal, UK National Nuclear Laboratory (NNL), Central Laboratory, Sellafield CA20 1PG, UK; ${ }^{c}$ Department of Materials, Imperial College, London SW7 2AZ, UK; ${ }^{d}$ Radioactive Waste Management Limited, Harwell OX11 ORH, UK
\end{abstract}

\begin{abstract}
Analysis of advanced gas-cooled reactor (AGR) simulated used nuclear fuels (SIMFuels) has been carried out using micro-Raman spectroscopy in order to understand the effect lanthanide species (e.g. Nd, Y, Ce), representative of fission products generated during fuel burnup, have on the structure of the $\mathrm{UO}_{2}$ matrix in spent AGR fuel. Results show a decrease in perfect fluorite character with increasing burnup as well as the development of a broad lattice distortion peak between 500 and $650 \mathrm{~cm}^{-1}$. Peak analysis of this broad band reveals in it comprised of three overlapping peaks at $534 \mathrm{~cm}^{-1}, 574 \mathrm{~cm}^{-1}$ and $624 \mathrm{~cm}^{-1}$. The peak at $534 \mathrm{~cm}^{-1}$ has been examined and is suggested to be due to a local phonon mode associated with oxygen-vacancy-induced lattice distortion as a result of lanthanide $3+$ ion incorporation into the $\mathrm{UO}_{2}$ bulk matrix.
\end{abstract}

Keywords: Raman microscopy; uranium dioxide; SIMFuel; advanced gas reactor

\section{Introduction}

In the UK, the vast proportion of spent nuclear fuel (SNF) is from indigenous advanced gas-cooled reactors (AGR). AGR reactors have several unique characteristics. First, the $\mathrm{UO}_{2}$ fuel is annular in shape and clad in stainless steel rather than zircalloy. Secondly, fuel assemblies are moderated via a graphite core and coolant exit temperatures are almost twice that of LWR reactors. With the shift in UK energy strategy towards geological disposal rather than reprocessing, understanding of the durability of AGR fuels under disposal conditions relevant to UK geology has become a pressing research area [1]. However, handling of highly radioactive AGR spent nuclear fuel presents many barriers to the detailed scientific study of such parameters. Thus, in 2011 a consortium of UK academic and industrial institutions was set up to create the first UK specific simulated spent AGR nuclear fuels (SIMFuel), providing low and high burn-up fuel surrogates that can be studied in low activity laboratories without the complication of an intense radiation field. A detailed microstructural analysis of these SIMFuel samples, including SEM-EDX and XRD measurements, has been previously reported [2,3]. SIMFuel has been found to be inhomogenous, containing a bulk $\mathrm{UO}_{2}$ matrix, noble metal particulates ( $\varepsilon$-phase particles) and perovskite precipitates (or 'grey phase').

Here we report a vibrational analysis of these

*Corresponding author. Email: c.boxall@lancaster.ac.uk materials using micro-Raman spectroscopy, with a focus on the effect lanthanide species ( $\mathrm{Nd}, \mathrm{Y}$ and $\mathrm{Ce}$ ), representative of fission products generated during fuel burnup, have on the vibrational spectrum of the bulk $\mathrm{UO}_{2}$ fuel matrix. Micro-Raman allows localized chemical state interrogation of the bulk $\mathrm{UO}_{2}$ matrix in SIMFuel not possible with either SEM-EDX or powder XRD. Such data is particularly useful in predicting the electrochemical corrosion behaviour of nuclear fuel, for example the degree of initial material oxidation [4] and the inhibiting effect lanthanide fission products may have on fuel dissolution [5].The use of micro-Raman for the analysis of stoichiometric $\mathrm{UO}_{2}$ [6], hyperstoichiometric $\mathrm{UO}_{2}$ [4] and doped $\mathrm{UO}_{2}$ materials [5] has seen much interest in the last 10 years. Through careful peak analysis, vibrational contributions in the Raman shift region $500-700 \mathrm{~cm}^{-1}$ have been assigned to oxygen vacancies (resulting from Ln3+ incorporation) and oxygen interstitials (and clusters of interstitials), the latter allowing determination of the oxygen to metal ratio (i.e. the degree of hyperstoichiometry).

\section{Experimental}

\subsection{Materials}

Depleted $\mathrm{UO}_{2}$ powder manufactured from $\mathrm{UF}_{6}$ was provided by National Nuclear Laboratory (Springfields, UK). All other chemicals were of AnalaR grade or better and supplied by either Alfa Aesar (Heysham, Lancashire, 
UK) or Sigma Aldrich (Gillingham, Dorset, UK).

\subsection{Preparation of AGR SIMFuel samples}

A detailed description of the preparation of undoped $\mathrm{UO}_{2}, 25 \mathrm{GWd} / \mathrm{tU}$ and $43 \mathrm{GWd} / \mathrm{tU}$ SIMFuel samples has been previously described elsewhere [2,3]. However, for the reader's convenience we briefly summarise the preparation process below:

Spent AGR fuel compositions for $25 \mathrm{GWd} / \mathrm{t} \mathrm{U}$ and 43 $\mathrm{GWd} / \mathrm{t} \mathrm{U}$ simulated burnup and after 100 years cooling, time were first calculated using FISPIN 10.0.1 code [3]. Due to their miscibility in urania and close periodicity $\mathrm{Pu}, \mathrm{Am}, \mathrm{Cm}, \mathrm{Sm}, \mathrm{Pr}, \mathrm{Pm}$ and $\mathrm{Np}$ were replaced by additional $\mathrm{UO}_{2}$, with the final simulated material composition shown in Table 1.

Table 1. FISPIN calculated AGR SIMFuel composition used to create the samples described here after 100 years cooling time for both 25 and $43 \mathrm{GWd} / \mathrm{t} \mathrm{U}$ burnup.

\begin{tabular}{ccc}
\hline $\begin{array}{l}\text { SIMFuel } \\
\text { Composition } \\
(\mathrm{at} \%)\end{array}$ & $\begin{array}{c}25 \mathrm{GWd} / \mathrm{t} \mathrm{U} \\
\text { Burnup }\end{array}$ & $\begin{array}{c}43 \mathrm{GWd} / \mathrm{t} \mathrm{U} \\
\text { Burnup }\end{array}$ \\
\hline $\mathrm{UO}_{2}$ & 95.705 & 92.748 \\
$\mathrm{Nd}_{2} \mathrm{O}_{3}$ & 0.761 & 1.284 \\
$\mathrm{ZrO}_{2}$ & 0.793 & 1.276 \\
$\mathrm{MoO}_{3}$ & 0.614 & 1.027 \\
$\mathrm{RuO}_{2}$ & 0.512 & 0.892 \\
$\mathrm{BaCO}_{3}$ & 0.328 & 0.576 \\
$\mathrm{CeO}_{2}$ & 0.297 & 0.499 \\
$\mathrm{PdO} \mathrm{Rh}_{2} \mathrm{O}_{3}$ & 0.195 & 0.425 \\
$\mathrm{La}_{2} \mathrm{O}_{3}$ & 0.080 & 0.115 \\
$\mathrm{SrO}_{\mathrm{Y} O}$ & 0.156 & 0.256 \\
$\mathrm{Y}_{2} \mathrm{O}_{3}$ & 0.081 & 0.126 \\
$\mathrm{Cs}_{2} \mathrm{CO}_{3}$ & 0.095 & 0.149 \\
$\mathrm{TeO}_{2}$ & 0.311 & 0.495 \\
\hline
\end{tabular}

A $60 \mathrm{~g}$ blend of each composition was then generated based on Table 1 . The blend was ball milled overnight using a $\mathrm{ZrO}_{2}$ milling medium. After repeated sieving, powders were pre-compacted into granulates at a pressure of $75 \mathrm{MPa}$. Next 0.2 wt. \% zinc stearate was added as a lubricant and slowly mixed in using a rotary mixer. The granulates were then pressed into green pellets in a uniaxial press by applying a pressure of 400 $\mathrm{MPa}$. Pellets were then sintered in a refractory metal furnace at a heating rate of $5{ }^{\circ} \mathrm{C} / \mathrm{min}$ to $300^{\circ} \mathrm{C}$, and then $15^{\circ} \mathrm{C} / \mathrm{min}$ to $1730^{\circ} \mathrm{C}$ under 99.5 at. $\% \mathrm{H}_{2}$ and 0.5 at. $\%$ $\mathrm{CO}_{2}$ atmosphere, for a total sintering time of 300 minutes. After cooling, the finished pellets were cut into slices ranging from $\sim 1-3 \mathrm{~mm}$ thick using a precision cut-off machine with diamond cut-off wheel and surface polished using 600 grit $\mathrm{SiC}$ paper.

\subsection{Raman analysis of AGR SIMFuel samples}

$\mu$-Raman Spectra were acquired using a Voyage confocal Raman microscope system (B\&W Tek, Newark, USA). All spectra were acquired at an excitation wavelength of $785 \mathrm{~nm}$. Before analysis, laser power was adjusted to $<5 \mathrm{~mW}$ using neutral density filters in order to avoid any thermal oxidation of $\mathrm{UO}_{2}$ to $\mathrm{U}_{3} \mathrm{O}_{8}$ [5]. Typical analysis of each sample involved focusing the laser beam on the sample through a $50 \mathrm{x}$ objective lens before taking a spectra using an integration time of 40000 milliseconds over a wavenumber range from 190 to $3000 \mathrm{~cm}^{-1}$. For the analysis of each sample, an average of 20 spectra were recorded at different locations across the sample, being careful to avoid any large noble metal ( $\varepsilon$-phase) particles or $\mathrm{BaZrO}_{3}$ phases $[7,8]$, in order to account for natural variations in oxygen to metal ratio in the SIMFuel bulk $\mathrm{UO}_{2}$ matrix [9].

\section{Results and discussion}

$\mu$ Raman spectra of undoped $\mathrm{UO}_{2}, 25 \mathrm{GWd} / \mathrm{t} \mathrm{U}$ and 43 GWd/t U AGR SIMFuel samples over the wavenumber range 300 to $800 \mathrm{~cm}^{-1}$ are shown in Figure 1.

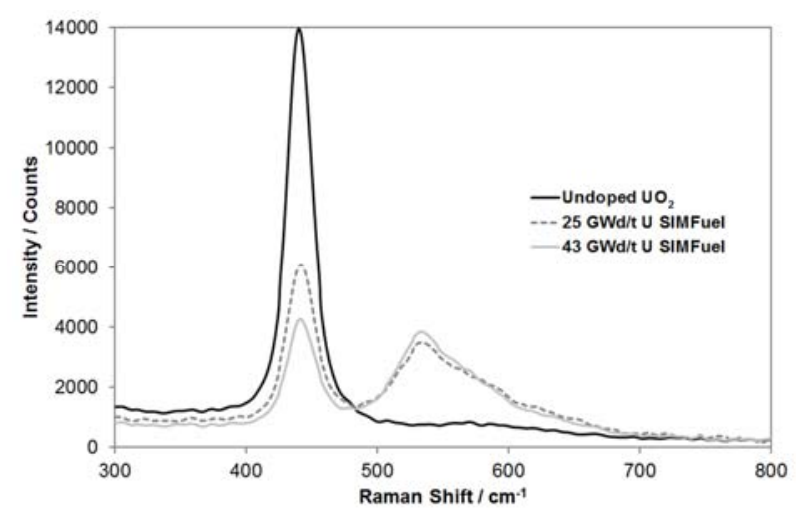

Figure 1. $\mu$ Raman spectra recorded from undoped $\mathrm{UO}_{2}, 25$ GWd/t U SIMFuel and $43 \mathrm{GWd} / \mathrm{t}$ U SIMFuel pellets.

Considering first the $\mu$-Raman spectrum of the undoped uranium dioxide sample in Figure 1, group theory predicts that a perfect fluorite structure would be expected to give a triply degenerate Raman active mode $\left(T_{2 g}\right)$ [10], frequently defined as the fundamental U-O symmetric stretching mode [5]. This intense vibration typically appears at $\sim 445 \mathrm{~cm}^{-1}$ and in our sample is very close to this value at $442 \mathrm{~cm}^{-1}$.

Turning now to the two SIMFuel samples, it can be seen from Figure 1 that there is a clear decrease in intensity of the U-O fundamental stretch with increasing simulated burnup. Such a marked decrease in this peak is indicative of movement away from a perfect fluorite lattice structure, either via non-stoichiometry or introduction of dopant defects [4,5]. Furthermore a new broad band is observed between $\sim 500$ and $650 \mathrm{~cm}-1$ and has been previously ascribed by $\mathrm{He}$ et al. as due to lattice distortions resulting from fission product doping [9].

In order to deconvolute the various component peaks that comprise the broad band between 500 and $650 \mathrm{~cm}^{-1}$ an initial linear baseline correction was carried out over 
the range $370-750 \mathrm{~cm}^{-1}$, followed by peak wavenumber identification based on the downward zero-crossings in the smoothed first derivative of the spectrum. Having determined the main contributors, a multiple unconstrained Lorentzian fit was conducted using an iterative least-squares fit at the obtained wavenumber values. An example of this analysis for the $25 \mathrm{GWd} / \mathrm{tU}$ simulated burnup SIMFuel sample is shown in Figure 2.

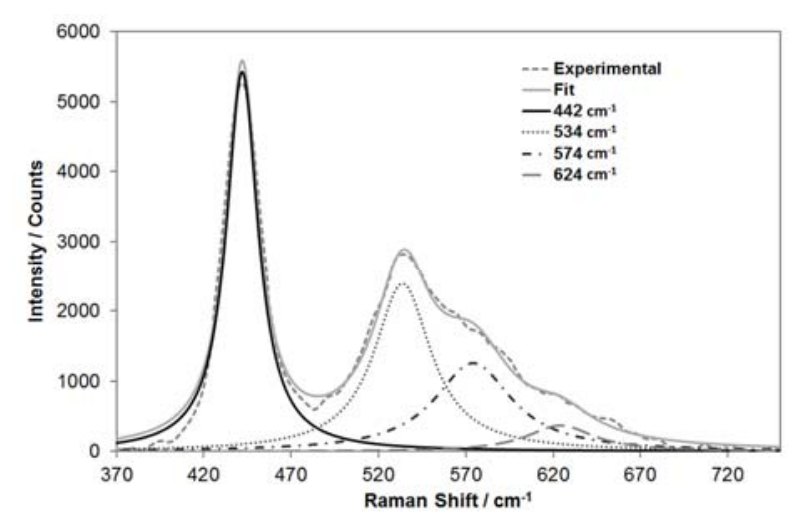

Figure 2. Example Lorentzian profile analysis of $25 \mathrm{GWd} / \mathrm{t} \mathrm{U}$ SIMFuel over the range of $370-750 \mathrm{~cm}^{-1}$.

For both SIMFuel samples, three overlapping peaks are identified as contributing to the broad band between 500 and $650 \mathrm{~cm}^{-1}: 534 \mathrm{~cm}^{-1}, 574 \mathrm{~cm}^{-1}$ and $624 \mathrm{~cm}^{-1}$. Here we focus on the origin of the $534 \mathrm{~cm}^{-1}$ peak of these samples.

The $534 \mathrm{~cm}^{-1}$ peak has previously been assigned in un-doped $\mathrm{UO}_{2}$ to various different effects. First, Livneh and Sterer [11] report that a degenerate phonon band with high density of states can be resolved at $515 \mathrm{~cm}^{-1}$. However, such a feature only appears in $\mathrm{UO}_{2}$ above ambient pressure and at laser excitation wavelengths different to that used here.

Under ambient pressure, both Guimbretière et al. [12] and, more recently Onofri et al. [13], report the appearance of a peak at $540 \mathrm{~cm}^{-1}$ in $\mathrm{UO}_{2}$ irradiated with $\mathrm{He}$ and $\mathrm{Kr}$ respectively. Guimbretière et al. [12] suggest that this peak could be $\mathrm{UO}_{2-x}$ hypostoichiometry defects, created as an accompaniment to $\mathrm{UO}_{2+x}$ hyperstoichiometry defects (i.e. interstitial oxygens entering the lattice).

As the samples of Figure 1 have not been irradiated or ion implanted, the large increase in the $534 \mathrm{~cm}^{-1}$ band in our SIMFuel samples must therefore be dopant related. Comparison with Raman spectra of CANDU/LWR SIMFuel samples by He et al. [9], reveals a similar peak at $540 \mathrm{~cm}^{-1}$. This feature is attributed by the authors to $(\mathrm{Ba}, \mathrm{Sr}) \mathrm{ZrO}_{3}$ perovskite precipitates within the sample. However, as noted in the experimental section, in this study care was taken to avoid noble metal ( $\varepsilon$-phase) particles or $\mathrm{BaZrO}_{3}$ phases within the SIMFuel materials, a discrimination not employed by He et al.. Thus, we are confident that spectra are only being acquired of the bulk $\mathrm{UO}_{2}$ matrix and the dissolved dopant oxides contained therein and we disagree with this previous assessment that the $534 \mathrm{~cm}^{-1}$ band is related to
$(\mathrm{Ba}, \mathrm{Sr}) \mathrm{ZrO}_{3}$ perovskite precipitates.

In support of the above assessment, alternative assignments for the $534 \mathrm{~cm}^{-1}$ peak have recently been provided by, Lee et al. [14], Razdan and Shoesmith [5], Desgranges et al. [15] and Talip et al. [16], through Raman measurements of Gd-doped $\mathrm{UO}_{2}$, Dy-doped $\mathrm{UO}_{2}$, $\mathrm{Nd}$-doped $\mathrm{UO}_{2}$ and La-doped $\mathrm{UO}_{2}$ respectively. In all cases the $530-540 \mathrm{~cm}^{-1}$ peak was found to increase with increasing lanthanide content. Furthermore, based on defect models by Park and Olander of Gd, Eu [17] and $\mathrm{Nd}$ [18] and Raman studies of lanthanide (III) doped $\mathrm{UO}_{2}[5,14-16]$, there is general agreement that the peak at $530-540 \mathrm{~cm}^{-1}$ is a local phonon mode associated with oxygen-vacancy-induced lattice distortion, said oxygen vacancies created as charge compensation for the incorporation of the $3+$ lanthanide dopant into the bulk $\mathrm{UO}_{2}$ matrix.

In order to assess differences in peak intensity between the two SIMFuels, the integrated peak area of the deconvoluted $534 \mathrm{~cm}^{-1}$ peak for both the $25 \mathrm{GWd} / \mathrm{t}$ $\mathrm{U}$ and $43 \mathrm{GWd} / \mathrm{t} \mathrm{U}$ was calculated and compared, with the results shown in Figure 3.

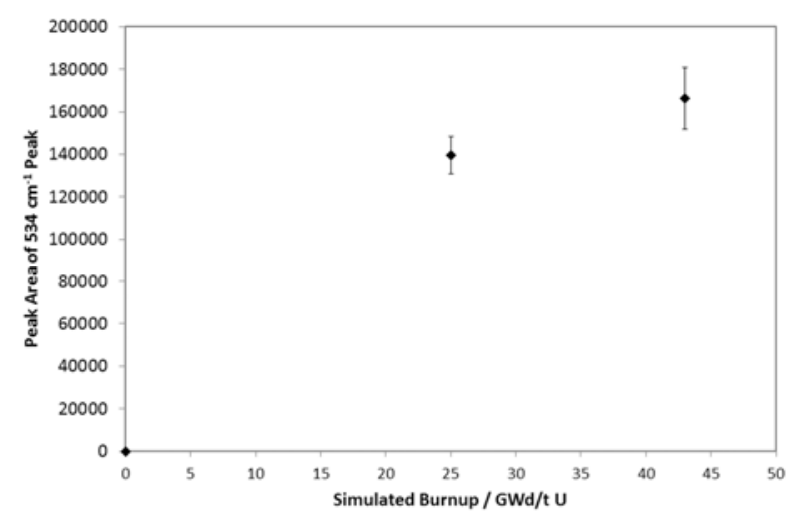

Figure $3.534 \mathrm{~cm}^{-1}$ peak area as a function of simulated burnup.

Figure 3, shows a significant increase in the $534 \mathrm{~cm}^{-1}$ peak with increasing burnup. From Table 1 it can be seen that the primary dissolved lanthanide oxide dopant is neodymium $(0.761$ at. $\%$ and 1.284 at. $\%$ in the 25 and $43 \mathrm{GWd} / \mathrm{t}$ U SIMFuel samples respectively), with much lower amounts of lanthanum also present (0.156 at. \% and 0.256 at. $\%$ respectively). There may also be some cerium dissolved in the matrix as well, although it is difficult to estimate how much, as some partitions into $(\mathrm{Ba}, \mathrm{Sr}) \mathrm{ZrO}_{3}$ phases [2,3]. Hence, as our measurements are only taken of areas comprised of bulk $\mathrm{UO}_{2}$ containing dissolved dopant oxides, the increase in the $534 \mathrm{~cm}^{-1}$ peak area with burnup in the SIMFuel samples of Figure 3 can be predominantly attributed to the formation of oxygen vacancies formed as a result of $\mathrm{Nd}$ and La doping. Finally, based on the calculations of Park [18], such oxygen vacancies may be found in the form of dopant-vacancy clusters, in the case of neodymium: (5U: V: 2Nd). Thus, Raman analysis of these materials suggests that, as previously proposed for LWR SIMFuel materials $[5,8,9]$, lanthanide fission products in AGR 
SIMFuel are dispersed throughout the $\mathrm{UO}_{2}$ matrix as a solid solution of dopant-vacancy clusters.

\section{Conclusion}

Analysis of the bulk matrix of simulated spent advanced gas-cooled reactor nuclear fuel has been carried out using micro-Raman spectroscopy. Results show a decrease in perfect fluorite character with increasing burnup as well as the development of a broad lattice distortion peak between 500 and $650 \mathrm{~cm}^{-1}$. Peak analysis of this broad band reveals in it comprised of three overlapping peaks at $534 \mathrm{~cm}^{-1}, 574 \mathrm{~cm}^{-1}$ and 624 $\mathrm{cm}^{-1}$. The peak at $534 \mathrm{~cm}^{-1}$ has been examined and is suggested to be due to a local phonon mode associated with oxygen-vacancy-induced lattice distortion as a result of lanthanide $3+$ ion incorporation into the $\mathrm{UO}_{2}$ bulk matrix, rather than the presence of a $(\mathrm{Ba}, \mathrm{Sr}) \mathrm{ZrO}_{3}$ perovskite as previously described in Raman analysis of CANDU/LWR SIMFuels. As such, and as has been previously proposed for LWR SIMFuels, lanthanide fission products in AGR SIMFuel are dispersed throughout the $\mathrm{UO}_{2}$ matrix as a solid solution of dopant-vacancy clusters.

\section{Acknowledgements}

RJW and CB are supported by The Lloyd's Register Foundation (LRF). The Lloyd's Register Foundation supports the advancement of engineering-related education, and funds research and development that enhances safety of life at sea, on land and in the air.

\section{References}

[1] Department of Energy and Climate Change, Implementing geological disposal: A Framework for the long-term management of higher activity radioactive waste, URN 14D/235, UK Government, (2014), pp.1-54.

[2] Z. Hiezl, D.I. Hambley, C. Padovani and W.E. Lee, Processing and microstructural characterization of a UO2-based ceramic for disposal studies on spent AGR fuel, J. Nucl. Mat. 456 (2015), pp.74-84.

[3] Z. Hiezl, Processing and microstructural characterization of $\mathrm{UO}_{2}$-based simulated spent nuclear fuel ceramics for the UK's advanced gas-cooled reactors, Thesis, Imperial College London, (2015), pp.1-260.

[4] H. He and D.W. Shoesmith, Raman spectroscopic studies of defect structures and phase transition in hyper-stoichiometric $\mathrm{UO}_{2+x}$, Phys. Chem. Chem. Phys. 12 (2010), pp. 8108-8117.

[5] M. Razdan and D.W. Shoesmith, Influence of trivalent-dopants on the structural and electrochemical properties of uranium dioxide $\left(\mathrm{UO}_{2}\right)$, J. Electrochem. Soc. 161 (2014), pp. H105-H113.

[6] J. Lv, G. Li, S. Guo and Y. Shi, Raman scattering from phonons and electronic excitations in $\mathrm{UO}_{2}$ with different oxygen isotopes, J. Raman Spectrosc. 47 (2015), pp. 345-349.

[7] J.I. Bramman, R.M. Sharpe, D. Thom, and G. Yates, Metallic fission-product inclusions in irradiated oxide fuels, J. Nucl. Mater. 25 (1968), pp. 201-215.

[8] P.G. Lucata, R.A. Verral, H.J. Matzke and B.J. Palmer, Microstructural features of SIMFUEL simulated high-burnup $\mathrm{UO}_{2}$-based nuclear fuel, $J$. Nucl. Mater. 178 (1991), pp. 48-60.

[9] H. He, P.G. Keech, M.E. Broczkowski, J.J. Noël and D.W. Shoesmith, Characterization of the influence of fission product doping on the anodic reactivity of uranium dioxide, Can. J. Chem. 85 (2007), pp. 702-713.

[10]G.C. Allen, Characterisation of uranium oxides by micro-Raman, J. Nucl. Mater. 144 (1987), pp. 17-19.

[11]T. Livneh and E. Sterer, Effect of pressure on the resonant multiphonon Raman scattering in $\mathrm{UO}_{2}$, Phys. Rev. B: Condens. Matter. 73 (2006), p. 085118.

[12] G. Guimbretière, L. Desgranges, A. Canizares, G. Carlot, R. Carabello, C. Jégou, F. Duval, N. Raimboux, M.R. Ammar and P. Simon, Determination of in-depth damaged profile by Raman line scan in a pre-cut $\mathrm{He}^{2+}$ irradiated $\mathrm{UO}_{2}$, Appl. Phys. Lett. 100 (2012), pp. 251914-1-251914-4.

[13]C. Onofri, C. Sabathier, H. Palancher, G. Carlot, S. Miro, Y. Serruys, L. Desgranges and M. Legros, Evolution of extended defects in polycrystalline $\mathrm{UO}_{2}$ under heavy ion irradiation: Combined TEM, XRD and Raman study, Nucl. Instrum. Methods Phys. Res., Sect. B 374 (2016), pp. 51-57.

[14]J. Lee, J. Kim, Y.-S. Youn, N. Liu, J.-G. Kim, Y.-K. Ha, D.W. Shoesmith and J.-Y. Kim, Raman study on structure of $\mathrm{U}_{1-y} \mathrm{Gd}_{y} \mathrm{O} 2_{-\mathrm{x}}(\mathrm{y}=0.005,0.01$, $0.03,0.05$ and 0.1 ) solid solutions, J. Nucl. Mater. 486 (2017), pp. 216-221.

[15]L. Desgranges, Y. Pontillon, P. Matheron, M. Marcet, P. Simon, G. Guimbretière and F. Porcher, Miscibility gap in the U-Nd-O phase diagram: A new approach of nuclear oxides in the environment?, Inorg. Chem. 51 (2012), pp. 9147-9149.

[16]Z. Talip, T. Wiss, P.E. Raison, J. Paillier, D. Manara, J. Somers and R.J.M. Konings, Raman and X-ray studies of uranium-lanthanum-mixed oxides before and after air oxidation, J. Am. Ceram. Soc. 98 (2015), pp. 2278-2285.

[17]K. Park and D.R. Olander, Defect model for the oxygen potentials of gadolinium- and europium-doped urania, J. Nucl. Mater. 187 (1992), pp. 89-96.

[18]K. Park, The oxygen potential of neodymia-doped urania based on a defect structure, J. Nucl. Mater. 209 (1994), pp. 259-262. 